\title{
Effect of media composition (carbon and nitrogen sources) on the production of bioemulsifier from Serratia marcescens S10
} تأثير مكونات الوسط الزرعي (مصادر الكاربون و النتروجين )على انتاج المستحلب الحياتي من بكتريا

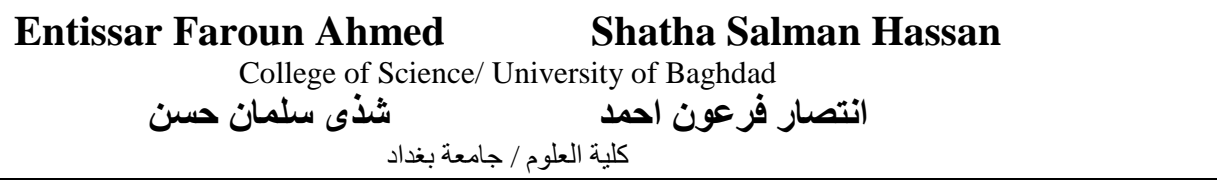

\section{Abstract}

The effect of different cultural conditions on production of bioemulsifier from Serratia marcescens S10 was determined; different carbon and nitrogen sources were used such as: different oils include: edible (vegetable) oils (olive oil, sesame oil, sun flower oil and corn oil) and heavy oils (oil 150, oil 60, oil 40) as carbon sources and $\left(\mathrm{NH}_{4} \mathrm{Cl}\right.$, casein, $\left(\mathrm{NH}_{4}\right)_{2} \mathrm{SO}_{4}$, peptone, tryptone, gelatin and yeast extract) as nitrogen sources were added to production media. Bioemulsifier was estimated by measuring the surface tension (S.T), emulsification activity (E.A) and emulsification index (E24\%). The best results of bioemulsifier production from Serratia marcescens $\mathrm{S10}$ were obtained at $\mathrm{pH8}$ and incubated at $37^{\circ} \mathrm{C}$ for 5days, using sesame oil as carbon source: surface tension (S.T) was reduced from 67 to $41 \mathrm{mN} / \mathrm{m}$ and with emulsification index (E24\%) of $92 \%$ and emulsification activity (E.A) 0.3 and when used ammonium sulfate as nitrogen source: highest results for the isolate S10: S.T was decreased from $67 \mathrm{mN} / \mathrm{m}$ to $24 \mathrm{mN} / \mathrm{m}, \mathrm{E} 24 \%$ $=88 \%$, E.A $=0.28$.

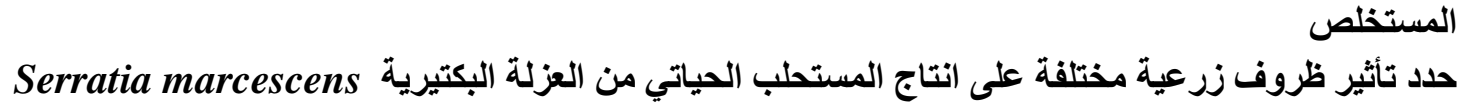

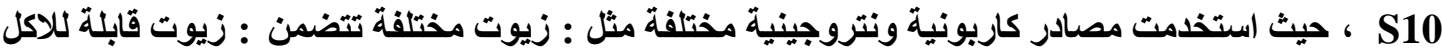

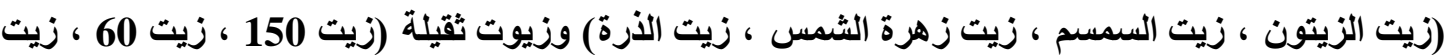

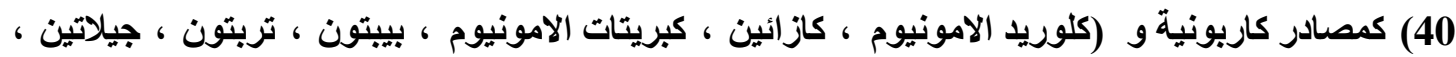

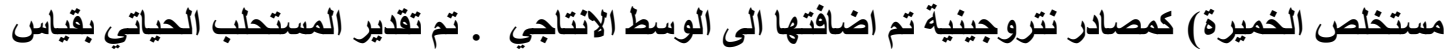

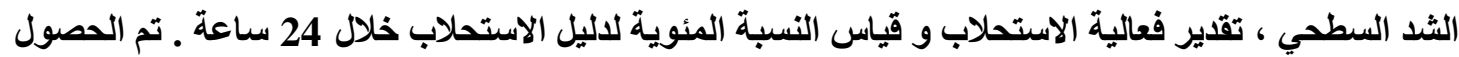

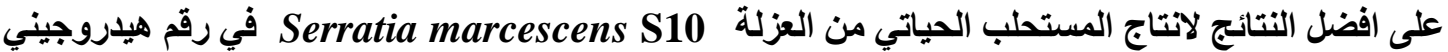

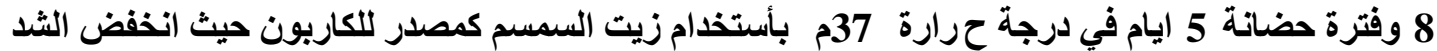

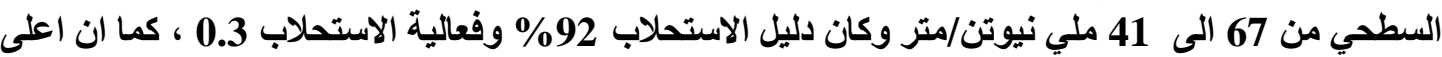

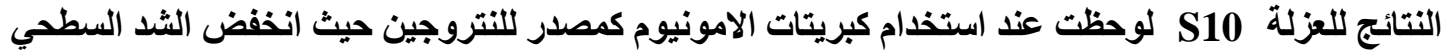

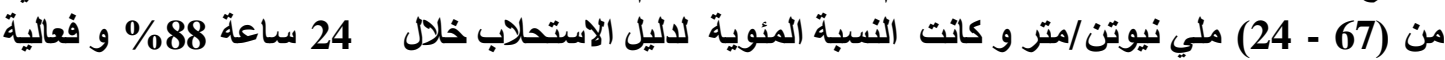

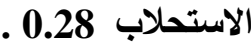

\section{Introduction}

Bioemulsifiers or biosurfactants are valuable microbial amphiphilic molecules with effective surface active and biological properties applicable in several industries and processes; environmentally it's more compatible than chemically synthesized rfactants [1]. Surfactants are Surface Active Agents with wide ranging properties including the

Keywords: Bioemulsifier, Serratia marcescens, surface tension, emulsification activity, emulsification index (E24\%), sesame oil. 
lowering of surface and interfacial tensions of liquids. Surface tension is defined as the free surface enthalpy per unit area, and is the force acting on the surface of a liquid leading to minimization of the area of that surface. Both synthetic and natural surfactants exist capable of reducing the surface tension of water from $72 \mathrm{mN} / \mathrm{m}$ toaround $27 \mathrm{mN} / \mathrm{m}$ [2].

Many factors affecting bioemulsifier production the most important factors are carbon and nitrogen sources in addition to other culture or environmental conditions, the carbon source used in bacterial culture is very important in biosurfactant production. In general it can be divided into three categories: carbohydrate, hydrocarbons and vegetable oils [3].

[4] noted that the amount of heavy crude oil metabolized by some bacterial species increased with increasing concentration of starter oil up to $0.6 \%(\mathrm{w} / \mathrm{v})$, the degradation rates appeared to be more pronounced between the concentrations of 0.4 and $0.6 \%(\mathrm{w} / \mathrm{v})$ oil.

Serratia marcescens can use medium containing glycerol as carbon source for production of biosurfactant, the yielded surfactant was identified as arabinolipid that is glycolipid containing arabinose sugar and C18:1 lipid moiety, the low - cost raw materials such as sunflower as carbon source give good yield of biosurfactant from Serratia marcescens [5].

In addition to carbon sources, nitrogen sources play an important role in the production of biosurfactants. Ammonium sulfate is considered as good nitrogen source for good production of biosurfactant from Serratia marcescens [6, 7].

This study reports the effect of carbon and nitrogen sources on the production of bioemulsifier by Serratia marcescens S10.

\section{Materials and methods}

\section{Isolation of bacteria}

Seventy-seven samples were collected from different sources (soils, water, foods, insects and clinical samples). Fourteen isolates were belonging to Serratia sp., the isolation was performed on: Nutrient, MacConkey and DNase agar and the identification was according to morphological and biochemical tests like: Oxidase, Catalase, Urease, Motility test \& also Identification by API 20 E System [8,9].

All Serratia sp. isolates screened for choosing the most active bioemulsifier producer isolate. Serratia marcescens $\mathrm{S} 10$ showed the highest production for bioemulsifier so it was selected for the following steps of this study.

\section{Production medium}

\section{A- Mineral salts broth}

This medium was prepared according to the methods described by $[10,11]$ by dissolving:

0.5 gm NH $\mathrm{NH}_{4} \mathrm{Cl}, 4 \mathrm{gm} \mathrm{NaCl}, 0.5$ gm $\mathrm{KH}_{2} \mathrm{PO}_{4}, 1$ gm $\mathrm{Na}_{2} \mathrm{HPO}_{4}$ and 0.5 gm $\mathrm{MgSO}_{4}$ $.7 \mathrm{H}_{2} \mathrm{O}$ in 1Liter distilled water, $10 \mathrm{ml}$ of olive oil (or any other oils) was added as carbon source. 


\section{B- Mineral salts media with different nitrogen source}

Mineral salts medium was prepared as in (paragraph $\mathrm{A}$ containing $\mathrm{NH}_{4} \mathrm{Cl}$ as nitrogen source) at $\mathrm{pH} 8$, the $\mathrm{NH}_{4} \mathrm{Cl}$ was replaced with $0.5 \mathrm{gm} / \mathrm{L}$ of different nitrogen sources included: (casein, $\left(\mathrm{NH}_{4}\right)_{2} \mathrm{SO}_{4}$, peptone, tryptone, gelatine and yeast extract) the media were sterilized by autoclave at $121^{\circ} \mathrm{C}$ for $15 \mathrm{~min}$.

C- Mineral salts medium with different kinds of oils (edible or vegetable and heavy oils)

Mineral salts broth $50 \mathrm{ml}$ was prepared as in (paragraph A) with adding $0.5 \mathrm{ml}$ of different oils like: edible or vegetable oils (olive, sesame, sun flower, corn) and heavy oils $(150,60,40)$, the $\mathrm{pH}$ of the medium was adjusted to optimum $\mathrm{pH} 8$ and sterilized by autoclave at $121^{\circ} \mathrm{C}$ for $15 \mathrm{~min}$.

\section{Methods}

\section{- Surface tension measurement}

The surface tension measurement (s) of cell free supernatant was determined in a K6 tensiometer, using the du Nouy ring method. All measurements were made on cellfree broth obtained by centrifuging the cultures at $10000 \mathrm{rpm}$ for $15 \mathrm{~min}$ [12].

\section{- Determination of emulsification index (E $24 \%$ )}

One $\mathrm{ml}$ of cell free supernatant was added to $1 \mathrm{ml}$ of kerosene or (oil) hydrocarbon (equal volumes v:v), mixed with vortex for $2 \mathrm{~min}$., and left for $24 \mathrm{hr}$. at room temperature, the height of emulsifier layer was measured. The E24 index is given as percentage of height of emulsified layer $(\mathrm{mm})$ divided by total height of the liquid column (mm) multiplying by 100 [13].

\section{- Determination of emulsification activity (E.A) by optical density}

The cells were separated from $50 \mathrm{ml}$ cultured mineral salts broth (containing $0.5 \mathrm{ml}$ olive oil) by centrifugation with cooling centrifuge at $4{ }^{\circ} \mathrm{C}$ and $5000-10000 \mathrm{rpm}$ for $30 \mathrm{~min}$., the emulsification activity was determined by taking $0.5 \mathrm{ml}$ of cell free supernatant and added to $7.5 \mathrm{ml}$ of Tris-Mg buffer \{ composed of $20 \mathrm{mM}$ ( Tris- $\mathrm{HCl}$ ) $(\mathrm{pH}=7)$ and $\left.10 \mathrm{mM}\left(\mathrm{MgSO}_{4}\right)[14]\right\}$ and $0.1 \mathrm{ml}$ of dodecane and mixed with vortex for $2 \mathrm{~min}$. the tubes were left for $1 \mathrm{hr}$. and absorbency was measured at $540 \mathrm{~nm}$. Emulsification activity was defined as the measured optical density; blank was Tris-Mg, dodecane and mineral salt broth without culture [15, 16].

\section{Result and Discussion}

\section{- Bacterial isolate}

Serratia marcescens S10 was isolated from the gut of the insect (American cockroach), which shows the highest ability to degradation of oils and hydrocarbons and production of bioemulsifier. It is non-spore forming, Gram negative and short rod. Results of biochemical tests showed that it was negative for oxidase, urease and positive for catalase, motility and DNase production.

\section{- Effect of carbon source}

The type, quality and quantity of bioemulsifier are influenced by the nature of carbon substrate. Media containing edible oils and heavy oils were used for production of bioemulsifier from $S$. marcescens S10. In general the edible oils (olive, sesame, corn, sun flower) were found more suitable for bioemulsifier production from S10. Among different edible (vegetable) and heavy oils, the sesame oil was the best carbon source 
in production of bioemulsifier, the results for $\mathrm{S} 10$ were $\mathrm{E} 24 \%=92 \%, \mathrm{~S} . \mathrm{T}$ decreased from 67 to $41 \mathrm{mN} / \mathrm{m}$, E.A = 0.3 Figure $(1 \mathrm{~A}$ and $\mathrm{B})$.

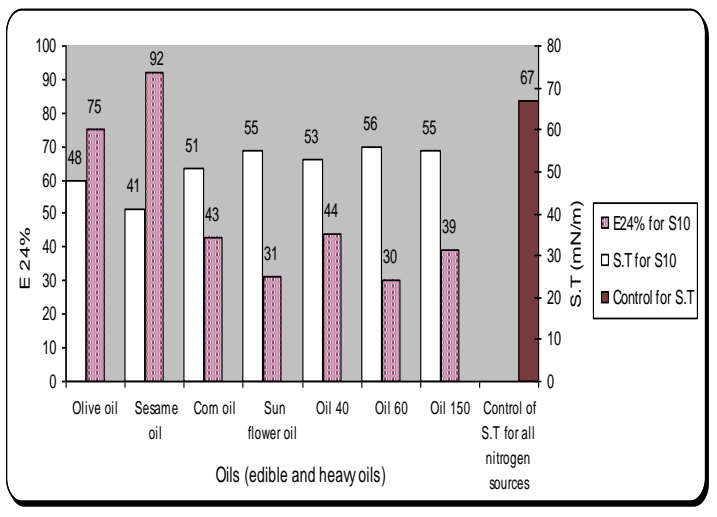

A

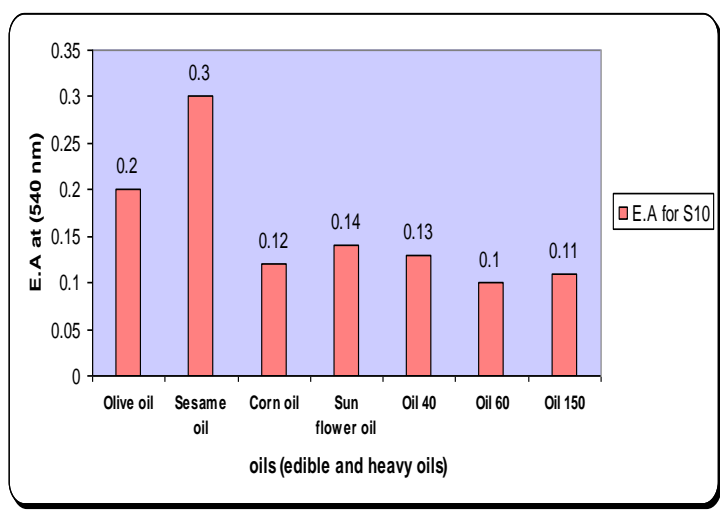

B

Fig (1): Effect of different oil sources on bioemulsifier production from S. marcescens $\mathbf{S 1 0}$ incubated at $37^{\circ} \mathrm{C}, \mathrm{pH} 8$ in shaker incubator for 5 days A- E24\% and S.T (mN/m) for S10 B- E.A at $540 \mathrm{~nm}$ for S10

Bacteria consume edible oil more easily than heavy oil because the heavy oils are more complex and may be toxic and difficulty to utilize as carbon source, while the edible oils are good carbon sources for growth and induction the bioemulsifier production.

Hydrophobic substrates like corn oil, lard (rich in unsaturated and saturated fat) and long chain alcohols induce microbial growth and metabolite production owing to their typical fatty acid composition by maximizing biosurfactant production [17].

[18] cultured two Serratia marcescens strains on minimal culture medium supplemented with vegetable oils, considering that it is well known that these compounds stimulate biosurfactant production, the vegetable oils included soybean oil, olive oil, castor oil, sunflower oil and coconut fat, the bacteria grew in this media, and there was a decreasing in surface tension of the culture medium from 64.54 to $29.57 \mathrm{mN} / \mathrm{m}$. Sunflower oil gave the best results (29.57) $\mathrm{mN} / \mathrm{m}$. Sunflower oil contains about $60 \%$ of linoleic acid, the addition of linoleic acid decreased the surface tension from 53.70 to $28.39 \mathrm{mN} / \mathrm{m}$ suggesting that this fatty acid stimulates the biosurfactant production by the Serratia marcescens LB006 strain, the crude surfactant reduced the surface tension of water from 72.00 to $28.70 \mathrm{mN} / \mathrm{m}$.

[19] noticed that sesame oil containing medium was more efficient in inducing pigment production and extracellular lipopeptide from $S$. marcescens comparing with nutrient broth or peptone glycerol broth.

\section{- Effect of nitrogen source}

Bioemulsifier production requires fine balance between carbon and nitrogen. One of the important factors that affected the growth and production of bioemulsifier from bacteria is the nitrogen source, because the bacteria require nitrogen to complete its metabolic pathways. In the present study among different organic and inorganic nitrogen sources the results proved that $\left(\mathrm{NH}_{4}\right)_{2} \mathrm{SO}_{4}$ is the best $(\mathrm{N})$ source for production of Serratia bioemulsifier, highest results for the isolate S10: E24\% $=88 \%$, S.T was decreased to $24 \mathrm{mN} / \mathrm{m}$, E.A $=0.28$ Figure ( $2 \mathrm{~A}$ and $\mathrm{B})$. 


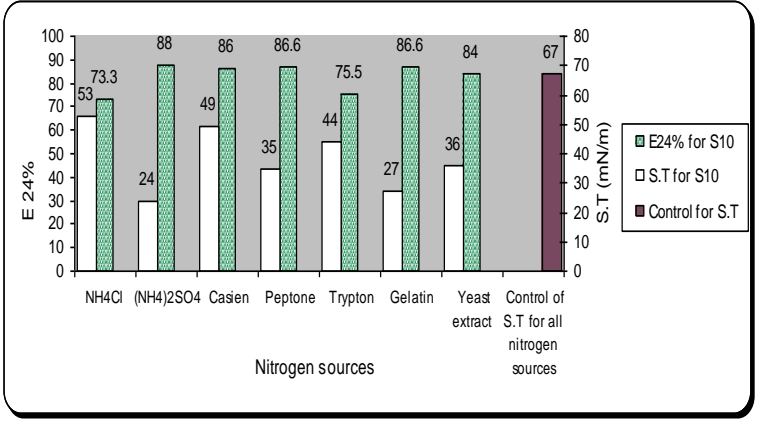

A

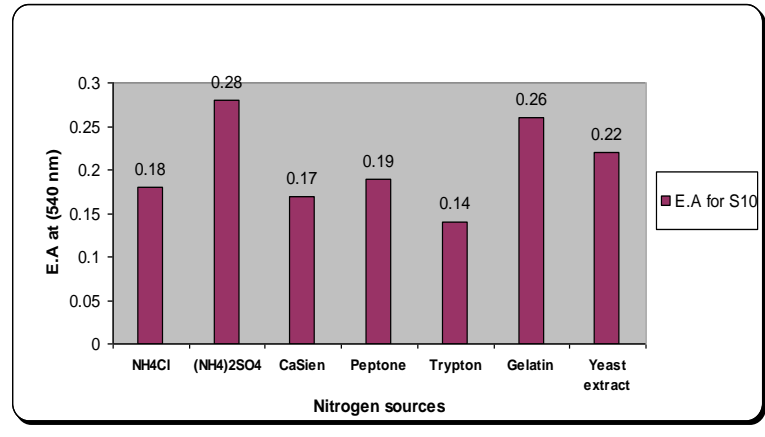

B

Fig (2): Effect of nitrogen sources $(0.05 \%)$ on bioemulsifier production from

S. marcescens $\mathrm{S10}$ at $37^{\circ} \mathrm{C}$, pH8 in shaker incubator for 5 days

A- E24\% and S.T (mN/m) for S10, B- E.A at $540 \mathrm{~nm}$ for S10

The maximum value of biosurfactant production may be attributed to the presence of ammonium sulfate; this salt is inorganic nitrogen source, very soluble and utilized easily as nitrogen source for cell metabolism and growth enhancing and may play a significant role in the pathways of emulsifier biosynthesis and/or extracellular secretion.

[20] reported that the Brazilian strain of Penicillium citrinum produced emulsifier using ammonium sulfate as a good nitrogen source and this emulsifier is very similar to biosurfactant extracted from $S$. marcescen .

\section{Conclusions}

The locally isolated Serratia marcescens (S10) which isolated from the gut of the insect (American cockroach) have the ability to produce glycolipid bioemulsifier; The production of bioemulsifier by $S$. marcescens (S10) enhance under optimum conditions of (sesame oil, $\left(\mathrm{NH}_{4}\right)_{2} \mathrm{So}_{4}, \mathrm{pH} 8$ and $37^{\circ} \mathrm{C}$ ) and it has the ability for utilization different oils but the utilization of edible oils was best than heavy oils.

\section{References}

1. Makkar, R. S. and Cameotra, S. S. (2002). "An update on the use of unconventional substrates for biosurfactant production and their new applications". Appl. Microbiol . Biotechnol. 58: 428-434.

2. Al-Araji, L.; Abd.Rahman, R. N.; Basri, M. and Salleh, A. (2007). "Minireview: Microbial surfactant". Asia Pacific Journal of Molecular Biology and Biotechnology. 15 (3): $99-105$.

3. Desai, J. D. and Banat, I. M. (1997). "Microbial production of surfactants and their commercial potential". Microbiology and Molecular Biology Reviews. 61 (1): 47-64.

4. Okoh, A. I.; Ajisebutu, S.; Babalola, G. O. and Trejo-Hernandez, M. R. (2002). "Biodegradation of Mexican heavy crude oil (Maya) by Pseudomonas aeruginosa ". J. Top. Biosci. 2 (1): 12-24.

5. Ferraz, C.; De Arújo, Á. A. and Pastore, G. M. (2002). "The influence of vegetable oils on biosurfactant production by Serratia marcescens'. Appl. Biochem. Biotechnology. 100 (1-3): 841-848. 
6. Pruthi, V. and Cameotra, S. S. (2000). "Novel sucrose lipid produced by Serratia marcescens and its application in enhanced oil recovery". Journal of Surfactant and Detergent. 3: $533-537$.

7. Banat, I. M.; Makkar, R. S. and Cameorta, S. S. (2000). "Potential commercial applications of microbial surfactants". Appl. M icrobiol. Biotechnol. 53: 495 - 508.

8. Atlas, R.; Brown, A. E. and Parks, L. C. (1995). Laboratory Manual Experimental Microbiology. Mosby -year Book, Inc.,Wesline Industerial Drive, St. Louis, Missouri.

9. Cruickshank, R.; Duguid, J. P.; Marmion, S. P. and Swain, R. H. A. (1975). Medical Microbiology: The Practice of Medical Microbiology. $12^{\text {th }}$ ed.Churchill Livingstone, Edinburgh.

10. Arutchelvi, J.; Bahaduri, S.; Uppara, P. V. and Doble, M. (2009)."Production and characterization of biosurfactant from Bacillus subtilis YB7". Journal of Applied Sciences. 9: $3151-3155$.

11. Al-Azawi , SH . S. (1982). The Effect of Microorganism on Asphaltic Concrete. MSc. Thesis. College of Science. University of Baghdad. (In Arabic)

12. Amiriyan, A.; Assadi, M. M.; Saggadian, V. A. and Noohi, A. (2004). "Bioemulsan production by Iranian oil reservoirs microorganism". Iranian J. Env. Health Sci Eng, 1 (2): 28 - 35.

13. Abouseoud, M.; Maachi, R.; Amrane, A.; Boudergua, S. and Nabi, A. (2008). "Evaluation of different carbon and nitrogen sources in production of biosurfactant by Pseudomonas fluorescence". J. Desalination, 223: 143 - 151.

14. Bach, H.; Berdichevsky, Y. and Gutnick, D. (2003). "An exocellular protein from the oil -degrading microbe Acinetobacter venetianus RAG-1 enhances the emulsifying activity of polymeric bioemulsifier Emulsan". Applied and Environmental Microbiology. 69 (5): 2608 - 2615.

15. Patel, R. N. and Desai, A. J. (1997). "Surface active propertiesof raminolipids from Pseudomonas aeroginosa GS3'. J. Basic Microbiol. 32: 518 - 520.

16. Sifour, M.; Al-Jilawi, M. H. and Aziz, G. M. (2007). "Emulsification properties of biosurfactant produced from Pseudomonas aeruginosa RB 28". Pakistan Journal of Biological Sciences. 10 (8): 1331 - 1335.

17. Mata-Sandoval, J.C.; Karns, J. and Torrents, A. (2000). "Effect of nutritional and environmental conditions on the production and composition of rhamnolipids by Pseudomonas aeroginosa UG2". Microbiol. Res. 155: 1-8.

18. Ferraz, C.; De Araújo, Á. A. and Pastore, G. M. (2007). "The influence of vegetable oils on biosurfactant production by Serratia marcescens". Applied Biochemistry and Biotechnology. 98 (1): 841-847.

19. Khanafari, A.; Assadi, M.M. and Fakhr, F.A. (2006). "Review of prodigiosin, pigmentation in Serratia marcescens". Online Journal of Biological Sciences. 6 (1): 1-13.

20. Camargo de Morais, M. M.; Ramos , S. A. F. ; Pimentel, M. C. B.; Melo, E. H. M.; Morais, M. A.; Kennedy, J. F. and Lima Filho, J. L. (2006). "Lipopolysacchride extracellular emulsifier produced by Penicillium citrinum'. Journal of Biological Sciences. 6 (3): 511-515. 